\title{
Correction to: \#P-completeness of Counting Update Digraphs, Cacti, and Series-Parallel Decomposition Method
}

\author{
Kévin Perrot, Sylvain Sené, and Lucas Venturini
}

\author{
Correction to: \\ Chapter "\#P-completeness of Counting Update Digraphs, \\ Cacti, and Series-Parallel Decomposition Method" \\ in: M. Anselmo et al. (Eds.): Beyond the Horizon \\ of Computability, LNCS 12098, \\ https://doi.org/10.1007/978-3-030-51466-2_30
}

The author originally listed as Camille Noûs on this conference paper [1] is fictitious (http://www.cogitamus.fr/indexen.html) and as such does not fulfill the requirements for authorship. The correct authorship list is: Kévin Perrot, Sylvain Sené and Lucas Venturini. This has been corrected.

[1] Perrot, K., Sené, S., Venturini, L.: \#P-completeness of Counting Update Digraphs, Cacti, and Series-Parallel Decomposition Method. In: Anselmo, M., Della Vedova, G., Manea F., Pauly, A. (eds.) CiE 2020. LNCS, vol. 12098, pp. 326-338. Springer, Cham (2020). https://doi.org/10.1007/978-3-030-51466-2_30 